\title{
O Parangolé e a expressão da identidade migrante
}

\author{
Vera Horn *
}

\begin{abstract}
A identidade constrói-se caminhando. José Eduardo Agualusa

O que era previamente considerado imutável é agora encarado como uma 'construção cultural', sujeita a variações tanto no tempo quanto no espaço.

Peter Burke
\end{abstract}

Como sublinha Maurizio Ambrosini (2009), por muito tempo, a imigração foi considerada um processo monodirecional, isto é, a transferência de um país para outro. Instaurava-se então um processo gradual de assimilação do imigrado na sociedade acolhedora e, posteriormente, dos descendentes, não desprovido de conflitos e tensões, e voltado para uma assimilação linguística de costumes e estilos de vida em prol da pertença ao novo mundo. Esse modelo, explica Ambrosini, que até os anos sessenta foi utilizado para explicar a inclusão dos imigrados, entrou em crise por diversos motivos (p. 673). Para o autor, uma dimensão saliente derivada do novo olhar sobre a relação entre migrantes e sociedades acolhedoras está em uma atenção muito maior à manutenção de elos com a origem, o cultivo de identidades mistas, a conservação, recuperação ou mesmo a reinvenção de traços culturais referentes ao patrimônio ancestral das populações em movimento (p. 674).

* Dra. em Estudos de Italianística pela Universidade de Pisa. 
Edward Said chamou a atenção para o problema da duplicidade vivida pelos exilados utilizando um termo musical: o contraponto. Para o autor, a maioria das pessoas conhece uma cultura e uma casa, mas os exilados conhecem pelo menos duas e essa perspectiva plural lhe permite uma consciência de dimensões simultâneas. Said também ressaltou o fato de os migrantes procurarem recriar nos países de imigração a terra que deixaram para trás para compensar a perda ou o sentimento de não pertencimento, "criando um novo mundo para governar": "esse novo mundo é artificial e sua irrealidade assemelha-se à ficção. No exílio, o isolamento provoca certo masoquismo narcisista, que resiste aos esforços de melhoramento, aculturação e adesão à outra comunidade" (SAID, 2003, p. 54).

A representação das identidades diaspóricas ou migrantes é frequente na literatura da migração, termo que se refere às obras produzidas por escritores não autóctones que escrevem na língua do país de imigração, mas que não conhece ainda uma concordância. No que se refere à chamada segunda geração ${ }^{1}$, ao invés do que pode parecer à primeira vista, o que se observa não é a predominância da dicotomia citada por Ambrosini entre o apego a uma identidade de origem ou à do país de chegada ou a preferência de segundas gerações pelo país de origem dos pais a que se refere Chris Weedon (2010), mas uma problemática e complexa teia de relações entre o país de ascendência e o país de residência.

Uma obra emblemática que problematiza extensamente a questão é Porto il velo adoro i Queen, de Sumaya Abdel Qader (2008), cujo título já nos leva a uma dimensão dupla e ao mesmo tempo vagamente provocatória ao colocar lado a lado o véu, associado ao Islã e que o senso comum relaciona de imediato a posições rígidas e a proibições variadas quanto à alimentação, ao vestuário ou aos próprios costumes, e o grupo de rock Queen. De fato, todas essas questões surgem no corpo do texto. No livro, definido por Martino Pillitteri "un po' blog, un po' letteratura" [meio blog, meio literatura] (PILLITTERI, s/d), a protagonista Sulinda, cujos dados biográficos espelham os da própria autora, nascida em Perugia, de pais jordanianos com ascendência palestinense, trinta anos, casada, com duas filhas, procura desconstruir ironicamente estereótipos vinculados a esses preconceitos, sobretudo porque, como afirma o título, ela usa o véu, o que contribui para acentuá-los. Seja de férias na praia, na academia, no cabeleireiro, na escola (sua ou das filhas), o fato de usar o véu precede sempre a nacionalidade quando visto pelo outro. Emblemática é a cena que se desenrola em frente a uma vitrine de uma conhecida loja de roupas íntimas: a protagonista se vê observada e, em um segundo momento, filmada por uma jornalista e um cinegrafista atônitos diante da cena: uma mulher de véu diante de um corpete preto de renda. O comportamento de Sulinda desta vez, como de outras, é irônico e aspira a uma deconstrução do preconceito. Talvez seja ainda mais notável o episódio em que suas filhas, duas meninas de quatro e seis anos, cantam o hino nacional italiano num ônibus em Milão. Ao mencionar a frase "Siam pronti alla morte" [Estamos dispostos a morrer], que faz parte do hino, as crianças escandalizam uma senhora, que conclui apressadamente sobre a tendência violenta de tais 
povos, o que, aliás, representa um outro tipo de estereótipo que a protagonista exprime quando de sua viagem aos EUA, ou seja, o que identifica o véu com o terrorismo islâmico e com Bin Laden por extensão. $O$ episódio conclui-se quando a senhora do ônibus apercebe-se do engano ao ouvir a continuação do hino pelas meninas: "L'Italia chiamò" [A Itália chamou] que dirime todas as dúvidas sobre a procedência do canto entoado pelas crianças e que não só chama a atenção para o fato de as crianças de origem árabe entoarem o hino italiano, mas para o fato de a tradicional senhora milanesa (a "sciura") [a senhora - forma dialetal] não ter reconhecido de imediato os versos do hino. Em uma inversão de perspectivas, Sulinda questiona a italianidade através de seus símbolos.

Por vezes, o sentimento de não pertença ultrapassa a ideia de comunidade em que se insere. De resto, sentir-se degredado na própria terra não é um sentimento novo na literatura e não se restringe aos escritores migrantes. Não é pois só na Itália que Sulinda enfrenta o preconceito de uma suposta origem estrangeira. 0 mesmo acontece quando a protagonista viaja para o exterior, para o país de origem dos pais ou para outros países árabes. Seus supostos hábitos estrangeiros estão perenemente em desacordo com os costumes locais, até mesmo no que se refere à alimentação, um elemento crucial no processo de conservação das identidades nas comunidades imigradas. Em uma visita à Jordânia, Sulinda e um primo que mora nos EUA decepcionam-se com a lojinha local de alimentos e manifestam o desejo de comprar "comida normal": biscoitos recheados, batatas fritas, salgadinhos de milho, Nutella, alimentos com que estão acostumados nos países de residência. O próprio tio da protagonista interpreta o gesto de forma exclusiva: "Mas vocês que são estrangeiros não se contentam com nada? Por que não comem as coisas locais, em vez de ficar procurando as porcarias daqueles países? Assim é melhor voltar para casa" (p. 63)². Ao passar pela caixa, a condição "estrangeira" de ambos é imediatamente identificada pela funcionária, que nota como apenas estrangeiros compram esse tipo de alimento. No mesmo supermercado, a própria Sulinda identifica a seção dedicada à Italian food com a ideia de casa: "Ah, la pasta! Casa, dolce casa." [Ah, massa! Lar, doce lar] (p. 64). Todavia nota-se em Sulinda, de certa forma, uma contradição aparente em relação à questão alimentar, pois durante a mesma viagem, ela reitera a sensação amorosa e confortável ao experimentar pratos preparados de acordo com a tradição jordaniana na casa de sua avó, o que a transporta a uma sensação de familiaridade, de casa: "vou para a cozinha e começo a sentir

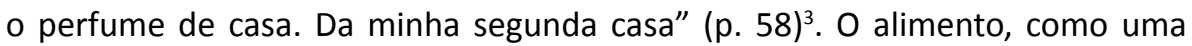
das mais poderosas construções identitárias, reflete, como em outros textos da literatura migrante, a ideia de casa ou, em outros textos, a reconciliação com o próprio eu. Mas para Sulinda as casas são duas.

É na mesma viagem que Sulinda manifesta o sentimento de saudade de casa, identificada com a Itália: "Depois de um tempo na Jordânia, geralmente depois de 10, 15 dias, a saudade de casa, da tua casa, começa a apertar" (p. $65)^{4}$, mas quando chega o dia da partida para a Itália, a protagonista, imersa 
em um sentimento de alienação em relação ao mundo circunstante, reflete interrogativamente: "torno a casa?" [estou voltando para casa?] (p. 66). A obra não aspira a uma reconciliação de pátrias, mas reflete constantemente sobre uma condição de afasia do migrante de segunda geração que, diante de situações ambíguas e da duplicidade de mundos, reflete sobre o sentimento de pertencimento que o liga a um país ou a outro para concluir por vezes que "é sempre a mesma coisa. Nem daqui, nem de lá" (p. 104)5. Estamos, ao mesmo tempo, diante de uma relação intrincada de valores e costumes que refletem ora um país e ora outro: "Por mais que me considere italiana, cresci com valores e um conceito de feminilidade bem diferentes dos das italianas da minha geração" (p. 108) $)^{6}$. Contraste semelhante reflete-se em outras situações em que o ser italiana da protagonista é frequentemente colocado à prova pelo fato de usar o véu, como nas limitações teatrais impostas pelo uso do véu (representar personagens que necessariamente podem usar véu), entre outras, como a praia e a piscina. As características físicas da protagonista, pele branca e olhos verdes, são justificativas fáceis para identificá-la como italiana, quando não há argumentos. Trata-se de uma situação narrada mais de uma vez, mas a que melhor representa um catálogo de estereótipos e preconceitos em relação à italianidade de Sulinda dá-se quando ela passeia com as filhas e a identificam com uma babá. Ela replica que é a mãe das crianças, o que leva a concluírem que é casada com um italiano. Mas como ela se identifica como italiana, a conclusão é imediata: é italiana porque tem pele clara e olhos verdes. Sulinda conclui: "che dire? Nulla" [O que dizer? Nada] (p. 55). A identidade da personagem passa pela interrogação da relação com o outro, incorporando esse outro na sua própria concepção identitária. Diante da perplexidade de ter que pedir permissão para poder viver "a casa mia" [na minha casa] (p. 30), a protagonista, declaradamente muçulmana, dirige-se a um ícone cristão e ocidental como Papai Noel (segundo Pilliteri, "miti idolatri non mussulmani" [mitos idólatras não muçulmanos]) para que seja reconhecida como italiana: "Mesmo que o Estado não me reconheça como filha sua, eu o sou. Sou uma nova italiana, mas não deixo de ser italiana!" (p. 29)7. Diversamente do imigrante de primeira geração, a segunda geração, nascida na Itália, não conta com um modelo identitário precedente, apesar dos pais imigrados. Sulinda declara-se italiana, mas apenas a alteridade lhe é reconhecida.

Os conceitos-chave explorados por Abdel Qader através da protagonista Sulinda, como representante de uma segunda geração (embora a autora rejeite o termo ${ }^{8}$ ) que manifesta a um tempo a consciência de estar dentro e fora ("a minha Itália será capaz de nos reconhecer causando o menor prejuízo?") (p. 177) ${ }^{9}$ e incerteza quanto à compreensão desse processo referem-se não tanto à experiência migratória, mas ao conceito de identidade cultural, casa e pertencimento.

O personagem Sulinda distingue-se, quanto à concepção identitária, de dois outros personagens de segunda geração: Anandita, do conto Curry di pollo, de 
Laila Wadia (2006) e Jean-Marie, do conto Solo allora, sono certo, potrò capire, de Tahar Lamri (2007).

Situação diametralmente oposta é representada por Anandita, cujos pais são radicalmente ligados à Índia, embora morem em Milão há mais de vinte anos, mas que deseja distinguir-se, rejeitando os costumes ligados à tradição indiana: recusa o pontinho na testa, recusa-se a passar óleo de coco no cabelo, usar sári, comer comida indiana: “Nesse verão, foi um desfile de túnicas e calças indianas, bolsas de juta com fotos de Bollywood, foulards de chiffon bordados com miçangas - parecia que todo o mundo queria ser indiano. Menos eu" ( $p$. 44-45) ${ }^{10}$. Anandita quer ser italiana, milanesa: quer usar salto alto, minissaia, ir à discoteca, ter um namorado, como todas as suas amigas italianas. De certa forma, ela não deseja a integração, mas a assimilação, que a diferencie dos pais, que considera "Flintstones indianos que ainda imaginam estar vivendo numa cabana de barro no desconhecido vilarejo de Mirapur, na Índia central, com duas vacas e três cabras" (p. 39) ${ }^{11}$. Por esse motivo, impõe à mãe que prepare penne [macarrão] ao molho de tomate (que o pai classifica como "tubi di gomma" [tubos de borracha]), e não o famoso curry di pollo [curry de frango] para o jantar em que o namorado estará presente. Itália, não Índia. Trata-se de um texto cuja veia irônica exacerba os pontos de contraste entre Anandita e os pais, ambos procurando fixar radicalmente uma identidade "sem costuras, inteiriça, sem diferenciação interna" (HALL, 1996, p. 110). É emblemático o gesto de Anandita de jogar na lata de lixo a merenda escolar preparada pela mãe: "Pão indiano recheado de verduras murchas e enrolado em papel alumínio, que consegue evitar o vazamento do óleo não mais que dez minutos" (p. 46) ${ }^{12}$. Ao deitar fora o pão indiano recheado de verduras, Anandita rejeita a cultura indiana de origem e procura reforçar sua italianidade: "o fato de que nasci e cresci na Itália" (p. 44) ${ }^{13}$, em franco constraste com os pais, ancorados em uma identidade marcada pela tradição, conforme a acepção de Stuart Hall, a qual se caracteriza pela tentativa de recuperar "sua pureza anterior e recobrir as unidades e certezas que são sentidas como tendo sido perdidas" (2006, p. 87). Ao analisar um determinado percentual da população indo-canadense de segunda geração, Kara Somerville observa que "a moda funciona como uma ferramenta cultural que constrói pontes entre fronteiras nacionais e permite que esses jovens se situem entre essas fronteiras"14 (SOMERVILLE, 2008). No conto, a rejeição de símbolos da cultura indiana, como a comida e as roupas, representa a ruptura de tais pontes.

Jean-Marie representa uma situação inversa em que a rejeição da cultura familiar (argelina) é levada a cabo pelo próprio pai para proteger a identidade francesa do filho e favorecer sua integração naquela cultura. Jean-Marie nasce na França, de pais argelinos, mas recebe um nome francês e é educado dentro dos moldes franceses. Com a morte do pai, Jean-Marie parte para a Argélia, onde descobre suas raízes e se reúne àquela parte dele que fora sepultada pelo pai em favor de uma suposta e forçosa integração: "Foi meu pai quem quis assim, porque para ele fazia parte da integração, da nossa, mas sobretudo, da minha 
integração na cultura francesa. Sabe, uma das tantas ilusões dos imigrados" (p. 16) ${ }^{15}$. Jean-Marie experimenta a sensação de integrar-se àquela realidade através dos pratos preparados pela família de Akli que o acolhe quando ambos perdem o voo para Paris: "parecia-Ihe estar viajando, numa viagem de retorno a si mesmo" (p. 29) ${ }^{16}$, tal como no romance do australiano Christopher Cyrill (1993), The Ganges and its Tributaries, "mexi o frango korma, acrescentei uma colherinha de sal (...) Enquanto eu mexia, imaginei que estava misturando as histórias que meu pai tinha me contado sobre a Índia" (p. 68) ${ }^{17}$. A viagem de Jean-Marie se traduz quase imediatamente no desejo de viver ali: "Vou voltar agora para Paris, arrumar minhas coisas e depois venho para cá definitivamente. Só então, tenho certeza, conseguirei compreender" (p. 33) ${ }^{18}$. As questões identitárias levantadas por JeanMarie quanto ao pertencimento e às raízes, em contraste com o personagem Akli, que rejeita tudo o que simbolicamente se refere ao país, não se resolvem em uma integração destituída de contrariedades e dúvidas. Como questiona Stuart Hall, "a categoria da identidade não é, ela própria, problemática?" (2006, p. 84). No que se refere à experiência de Jean-Marie podemos afirmar, com Stuart Hall, que toda identidade carrega um excesso, algo a mais à sua margem. A homogeneidade pretendida por seu pai "não é uma forma natural, mas uma forma construída de fechamento: toda identidade tem necessidade daquilo que lhe 'falta' - mesmo que esse outro que lhe falta seja um outro silenciado e inarticulado" (HALL, 1996, p. 110).

Stuart Hall define a identidade como uma construção discursiva em que os indivíduos se localizam individual e socialmente (HALL, 1996, p. 103; 109). Hall adverte, no entanto, que as identidades não são unificadas, mas estão sujeitas a uma historicização radical e apresentam-se em constante processo de mudança e transformação, dependendo das representações e interpelações dos sistemas culturais que nos rodeiam. Justamente porque são construídas dentro do discurso, e não fora, é que precisam ser compreendidas por meio da diferença e em relação a práticas discursivas, contextos e localização específicos (HALL, 1996, p. 108-110). A identidade é vista, portanto, como uma concepção flexível, fragmentária e resultado fugaz de um processo de identificação: "ela permanece sempre incompleta, está sempre 'em processo', sempre 'sendo formada'" (HALL, 2006, p. 38). Os três personagens de segunda geração não atravessaram fronteiras geográficas, mas cresceram em uma família estrangeira em um país estrangeiro. No entanto, os três representam, cada um individualmente, concepções identitárias diversas, ancoradas em uma percepção móvel ou fixa da ideia de fronteira. Essa não é definida somente por uma noção geográfica de linha de confim entre países, mas pode ser vista igualmente como uma linha divisória entre o dentro e o fora, na mesma nação. Tendo crescido em Milão e desejando assimilar-se aos usos e costumes milaneses para se sentir milanesa - ou italiana -, Anandita percebe a fronteira indiana como distante e considera-se parte da comunidade estrangeira que os pais não reconhecem como deles. Jean-Marie atravessa uma fronteira 
proibida - a terra, a língua árabe, os pratos da tradição - em um percurso inverso, tendo vivido inflexivelmente na fronteira francesa, a partir do qual busca definir o sentido do pertencimento: “(...) as 'identidades' só podem ser lidas a contrapelo, isto é, não como aquilo que fixa o jogo da diferença em um ponto de origem e estabilidade, mas como aquilo que é construído na différance (sic.) ou por meio dela, sendo constantemente desestabilizadas por aquilo que deixam de fora" (HALL, 1996, p. 111). No caso de Jean-Marie, a unidade identitária concebida pelo pai revela-se inteiramente artificial, provocando no personagem um processo de identificação posterior.

$\mathrm{Na}$ apresentação ao seu Intervista sull'identità, Zygmunt Bauman (2006) narra que se viu em dificuldade quando foi obrigado a escolher entre o hino inglês e o polonês para a entrega do título honoris causa na Universidade de Carlos, em Praga. A Polônia é seu país de origem, mas a Inglaterra é o país que ele escolhera e que igualmente o escolhera, oferecendo-lhe uma cátedra quando fora proibido de lecionar na Polônia. Bauman refere esse episódio por conter in nuce alguns dos dilemas que tendem a fazer da identidade "uma questão de graves preocupações e controvérsias acesas"19 (BAUMAN, 2006, p. 5). Em sintonia com as questões postas por Bauman, a protagonista de Porto il velo adoro i Queen pondera: "O País em que a gente nasce e cresce nos cria mil problemas, já o País de origem cria outros. Ou seja, somos jogados de um lado para outro e ninguém nos reconhece. Somos realmente filhos de sei lá quem" ( $p$. $13)^{20}$. Pelo fato de ter saído de seu "ambiente original", Varsávia, Bauman passou a se sentir fora de lugar em qualquer lugar. Essa situação, segundo o autor, pode gerar desconcerto, irritação. Há sempre algo a explicar, justificar, esconder, mostrar, negociar, contratar; há diferenças que precisam ser aplainadas ou, pelo contrário, evidenciadas, como Sulinda revela nos trechos:

De um lado estão os italianos (os que deveriam ser meus concidadãos), que costumam fazer as rotineiras perguntas mais ou menos inúteis, tipo se tenho cabelo por baixo do véu, como é que consigo fazer amor vestida desse jeito e outras amenidades do gênero. (...) Do outro, estão os parentes, ou os árabes em geral, que ficam no meu pé porque acham que sou 'ocidental demais' (p.13) (...) Nesta situação confusa é fácil perder o rumo, enganar a nós mesmos e aos outros querendo parecer o que não somos $(\text { ABDEL QADER, 2008, p. 14) })^{21}$.

A problemática identificada por Bauman e significativamente representada no texto de Abdel Qader indica a existência de uma questão relacionada a das identidades atribuídas e impostas. Vivemos, segundo Bauman, entre os que têm a possibilidade de compor e decompor a identidade da forma que preferem e os que se veem diante de identidades impostas das quais não podem descolarse, identidades estereotipadas, humilhantes, estigmatizadoras. Essa questão não 
passa despercebida pela autora, que colhe, ora do lado italiano-ocidental, ora do lado jordaniano-palestino-árabe, "fardos" identitários que lhe são impostos e que procura desconstruir ironicamente:

No meu "País", muitos têm olhos claros, não somos terroristas, nem todas as mulheres são submissas como certas pessoas gostam de espalhar por aí, o 11 de setembro é coisa de desgraçados, o conflito árabe-palestinense é proveitoso para alguns, o buraco do ozônio não é tão grave como parece, a máfia não tem nada a ver com a gente (ABDEL QADER, 2008, p. 44-45) ${ }^{22}$.

Como salienta Bauman, estamos sempre suspensos entre essas duas extremidades, sem saber até quando poderemos escolher o que desejamos e recusar o que não nos agrada. A protagonista reflete ainda acerca do problema no episódio em que uma mulher egípcia a observa falar em italiano com as filhas em Milão: "acho mais fácil falar com elas em italiano" 23 e reprova, com a convicção de que falar árabe com os filhos é condição indispensável para ser um "bom muçulmano": "berché barli con i tuoi figli in italiano? (...) e lei attacca con una predica dicendo che per i musulmani è obbligatorio parlare arabo, perché è la lingua del Corano." [por que você fala com seus filhos em italiano? (...) e começa a fazer um sermão, dizendo que os muçulmanos devem falar árabe, pois é a língua do Alcorão] (p. 55. Neste trecho, a escritora procura reproduzir a troca do " $p$ " pelo " $b$ " na fala da mulher egípcia). Não se trata de um evento isolado, entre os narrados pela protagonista, e reflete a condição explicitada por Bauman quando menciona o direito de reivindicar uma identidade distinta da classificação atribuída ou imposta (BAUMAN, 2006, p. 44). A protagonista não escolhe uma integração sem problemas ou uma conciliação aparentemente pacífica, mas opta por uma concepção identitária complexa, em camadas móveis.

Em 1964, Hélio Oiticica criou o primeiro parangolé, inspirado no espaço criado por um morador de rua onde vislumbrara a palavra "parangolé". Essa obra de Oiticica consiste em uma espécie de capa (ou tenda, bandeira e estandarte) multicolorida, que desfralda plenamente suas possibilidades de tons, cores, texturas somente quando o usuário a veste ou dança com ela: o parangolé revela-se na interação com o usuário. Trata-se, portanto, de uma construção progressiva. Segundo Silva,

o parangolé funda seu território momentâneo que se estabelece no ato da criação coletiva do acontecimento do evento para depois o abandonar, pois não pretende demarcar um solo ou pertencer a ele. Diferindo, assim, do processo arquitetural, consolidador dos Penetráveis e Ninhos, que possuem um caráter arborescente, de pertencimento a uma terra (SILVA, 2006, p. 54). 
Sulinda descreve-se como uma composição de identidades culturais e não concebe, pois, uma fronteira fixa, mas em permanente movimento e construção: "contribuíram para construir uma parte de mim, realizando aquele mosaico que sou, um mosaico em contínua transformação" (p. 179) ${ }^{24}$. A identidade-parangolé expressa por Sulinda e em parte por Jean-Marie atravessa fronteiras móveis que não são apenas geográficas. Sulinda não procura fixar papéis rígidos, como quando escolhe uma escola de freiras para as filhas, embora professe a religião islâmica e frequente uma mesquita em Milão. Ela afirma uma identidade plural e parcial que Salman Rushdie descreve em Pátrias imaginárias:

Somos hindus que atravessamos as negras águas; muçulmanos que comem carne de porco. E o resultado - e esta é minha noção do Pecado Original - é que fazemos parte integral do Ocidente. A nossa identidade é ao mesmo tempo plural e parcial. Às vezes sentimos que oscilamos entre duas culturas; outras vezes, que sentamos entre duas cadeiras (RUSHDIE, 1994, p.30).

A identidade-parangolé de Sulinda responde à concepção das identidades fragmentadas de Stuart Hall, compostas de várias identidades, algumas contraditórias ou não resolvidas: "a identidade torna-se uma 'celebração móvel': formada e transformada continuamente em relação às formas pelas quais somos representados ou interpelados nos sistemas culturais que nos rodeiam" (p.13), pois, como afirma o autor, "a identidade plenamente unificada, completa, segura e coerente é uma fantasia" (p. 13). Para a protagonista de Porto il velo adoro i Queen, "o verdadeiro desafio é viver uma identidade

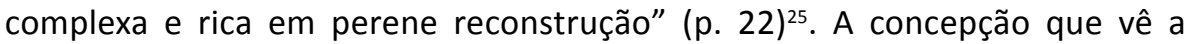
identidade como fixa e imutável é uma forma de construir a homogeneidade que não corresponde ao processo de identificação que estamos vivendo, que se tornou "mais provisório, variável e problemático" (HALL, 2006, p. 12). Essa "mobilidade" associa-se à dimensão móvel do parangolé, que vai desfraldando cores e cenários, formando e transformando-se continuamente, de acordo com os movimentos de quem o veste.

Como adverte Silva, o parangolé "não pretende demarcar um solo ou pertencer a ele" (2006, p. 54) e difere, portanto, dos Penetráveis e Ninhos (obras de Hélio Oiticica), que possuem um caráter arborescente, de pertencimento a uma terra (op. cit.), tal como a concepção identitária que se apreende da obra de Abdel Qader, na qual podemos identificar um aspecto rizômico, como explicita Quaquarelli, a partir de Glissant (2005), que retoma o termo de Deleuze e Guattari aplicando-o à identidade cultural: "Uma identidade crioula, e não mestiça, que se esparrama, se emaranha em outras raízes, dando início a processos identitários imprevisíveis" (QUAQUARELLI, 2006, p. 64) ${ }^{26}$. O próprio Glissant propõe que a identidade seja entendida na forma de um mosaico, forma com que a protagonista identifica sua concepção identitária. Os homens 
e culturas não são, mas estão: eles não possuem um ser específico, mas estão sempre em movimento e em mutação contínua na Relação. Apesar de desejar um reconhecimento como cidadã italiana, Sulinda não procura distinguir uma raiz totalitária, italiana ou jordaniana, pois sua reflexão aponta para um caráter híbrido em constante negociação. Emblemática nesse sentido é a cena em que a protagonista reflete-se no espelho com véu, jaqueta e calça comprida, ao som de Io non mi sento italiano, de Giorgio Gaber, cujas palavras Ihe soam estranhas. O rizoma pressupõe a formação de uma rede complexa de relações, pois supõe a existência de múltiplos percursos. Não é possível distinguir uma raiz porque o que existe é um rizoma, que rejeita a ideia de uma raiz totalitária, "da identidade não mais como raiz única, mas como raiz indo ao encontro de outras raízes" (GLISSANT, 2005, p. 27) que criam inter-relações preservando a diversidade. A identidade da protagonista define-se na interação: identidade-parangolé.

\section{Notas}

1 - A segunda geração é um conceito problemático na Itália, país cuja imigração ainda é jovem. Em linhas gerais, entende-se por segunda geração aquela que é nascida na Itália ou chegou ao país durante a infância e que tem ao menos um genitor estrangeiro. No entanto, refere-se aqui à segunda geração como personagem.

2 - "Ma voi stranieri non vi accontentate mai? Perché non accettate di mangiare le cose locali anziché cercare la robaccia di quei Paesi? Fate prima a tornare a casa vostra."

3 - "Salto in cucina e comincio a respirare profumo di casa. La mia seconda casa."

4 - “Dopo un po' che sei in Giordania, generalmente dopo 10-15 giorni, la nostalgia di casa, di casa tua, comincia a diventare pressante."

5 - "È sempre la solita storia. Né di qua né di là."

6 - "Per quanto mi ritenga italiana, sono cresciuta con certi valori e un'idea di femminilità sicuramente diversi da quelle delle mie coetanee indigene".

7 - "Anche se lo Stato non mi riconosce come sua figlia, io lo sono. Nuova italiana, ma lo sono!" 8 - A autora recusa a expressão por considerá-la um modo de sublinhar a diversidade, associada, nesse caso, ao estado de imigrante, cuja acepção é significativamente negativa ( $p$. 15).

9 - "La mia Italia sarà capace di riconoscerci facendo meno danni possibile?"

10 - “'Quest'estate c'era un tale sfoggio di tuniche e pantaloni indiani, borse di iuta con foto di Bollywood, foulard di chiffon ricamati con le perline - pareva che tutti volessero essere indiani. lo, però, no."

11 - "Dei Flintstones indiani que pensano di vivere ancora in una capanna di fango nell'oscuro villaggio di Mirapur, nell'India centrale, con le loro due mucche e le tre capre."

12 - "Pane indiano farcito con verdure defunte avvolte in carta stagnola che riesce a tamponare la fuoriuscita d'olio per dieci minuti circa."

13 - "Il fatto che sono nata e cresciuta in Italia."

14 - "Fashion serves as a cultural tool for building bridges across national boundaries and enables these youth to situate themselves between these boundaries."

15 - "L'ha voluto mio padre, perché per lui faceva parte dell'integrazione, secondo lui... della nostra, e soprattutto mia, nella cultura francese. Sa, una delle tante illusioni degli immigrati." 16 - "Gli sembrava di essere in viaggio, nel viaggio del ritorno verso di sé."

17 - "I stirred chicken korma, added a teaspoon of salt (...) As I stirred I imagined that I was combining the stories my father had told me about India." 
18 - "Adesso torno a Parigi, sistemo le mie cose e poi vengo a stabilirmi definitivamente qui. Solo allora, sono certo, potrò capire."

19 - "Una questione di gravi preoccupazioni e accese controversie."

20 - "Il Paese in cui nasci e cresci ti dà mille problemi, il Paese d'origine te ne dà altri. Insomma, ti sballottano da una parte all'altra e nessuno ti riconosce. Siamo davvero dei figli di chissà chi." 21 - "Da un lato ci sono gli italiani (quelli che dovrebbero essere i tuoi concittadini), che ti fanno le solite domande più o meno inutili, del tipo se sotto il velo hai i capelli, come fai a fare sesso vestita così e altre amenità simili. (...) Dall'altro ci sono i parenti, o gli arabi in generale, che ti assillano perché sei 'troppo occidentale' (p.13) (...) In questa situazione confusa è facile disorientati, ingannare se stessi e gli altri volendo apparire ciò che non si è".

22 - "Al mio 'Paese' in tanti hanno gli occhi chiari, non siamo terroristi, le donne non sono tutte sottomesse come qualcuno vuol far credere, l'11 settembre è opera di disgraziati, il conflitto arabo-israeliano fa comodo a qualcuno, il buco dell'ozono non è così grave come sembra, la mafia non ha niente a che vedere con noi" (p. 44-45).

23 - "Generalmente mi è più facile comunicare con loro in italiano."

24 - "Hanno contribuito a costruire una parte di me realizzando quel mosaico che sono, un mosaico in continuo divenire."

25 - "La vera sfida è vivere un'identità complessa e ricca che verrà continuamente sottoposta a riassestamenti e modifiche."

26 - "Un'identità creola e non meticcia, che va verso l'esterno, si annoda ad altre radici, innescando processi identitari imprevedibili."

\section{Referências}

ABDEL QADER, Sumaya. Porto il velo adoro i Queen. Milano: Sonzogno, 2008.

AMBROSINI, Maurizio. La costruzione delle identità trasversali: relazioni e appartenenze sociali attraverso i confini. In: CORTI, Paola e SANFILIPPO, Matteo (orgs.). Storia d'Italia. Annali 24. Migrazioni. Torino: Einaudi, 2009. p. 673-690.

BAUMAN, Zygmunt. Intervista sull'identità. A cura di VECCHI, Benedetto. Roma/Bari: Laterza, 2006.

CYRILL, Christopher. The Ganges and its Tributaries. Hawthorn: Penguin, 1993.

GLISSANT, Édoard. Introdução a uma poética da diversidade. Juiz de Fora: UFJF, 2005.

HALL, Stuart. A identidade cultural na pós-modernidade. Trad. Tomaz Tadeu da Silva e Guacira Lopes Louro. Rio de Janeiro: DP\&A, 2006.

HALL, Stuart. Quem precisa da identidade? In: SILVA, Tomaz Tadeu (org.). Identidade e diferença. Petrópolis: Vozes, 1996.

LAMRI, Tahar. I sessanta nomi dell'amore. Napoli: Tracce diverse, 2007.

OITICICA, Hélio. Aspiro ao grande labirinto. Rio de Janeiro: Rocco, 1986.

PILLITTERI, Martino. Porto il velo, adoro i Queen. Il sole 24 ore. Disponível em: <http://www. ilsole24ore.com/art/SoleOnLine4/Tempo\%20libero\%20e\%20Cultura/2008/11/portovelo-adoro-queen_2.shtml > Acesso em: 4 dez. 2011.

QUAQUARELLI, Lucia. Salsicce, curry di pollo, documenti e concorsi. Scritture dell'immigrazione di 'seconda generazione'. In: Narrativa. Paris: CRIX-Université Paris 10, n. 28, p. 53-65, nov. 2006.

RUSHDIE, Salman. Pátrias imaginárias. Ensaios e textos críticos, 1981-1991. Trad. Helena Tavares, Ana Vilela e Filomena Pereira. Lisboa : Dom Quixote, 1994.

SAID, Edward. Reflexões sobre o exílio e outros ensaios. Trad. Pedro Maia Soares. São Paulo: Cia das Letras, 2003.

SILVA, Cinara A. Hélio Oiticica - Arte como experiência participativa. Dissertação de Mestrado. Niterói: Universidade Federal Fluminense, 2006. Disponível em: <http://www.bdtd.ndc. uff.br/tde_arquivos/34/TDE-2006-10-02T131916Z-391/Publico/UFF-Dissert-CinaraSilva. 
pdf > Acesso em: 12 nov. 2011.

SOMERVILLE, Kara. Transnational belonging among Second generation youth: identity in a globalized world. Journal of Social Sciences. Special Volume. Delhi: Kamla-Raj, n. 10, p. 23-33, 2008. Disponível em: <http://www.krepublishers.com/06-Special\%20VolumeJournal/JSS-00-Special\%20Volumes/JSS-SV-10-Youth-Migration-Web/JSS-SV-10-03-02308-Somerville-K/JSS-SV-10-03-023-08-Somerville-K-Tt.pdf > Acesso em: 12 nov. 2011.

WADIA, Laila. Curry di pollo. In: WADIA, Laila et al. Pecore nere. Roma-Bari: Laterza, 2006. p. 39-52.

WEEDON, Chris. Identity and culture. Narratives of difference and belonging. England: Open University Press, 2010.

\title{
RESUMO
}

O artigo analisa o romance Porto il velo adoro i Queen (2008), de Sumaya Abdel Qader, italiana de origem jordaniana e palestina, no qual procura desconstruir os estereótipos relacionados a essa condição dupla e aos "fardos" identitários que lhe são impostos. A consciência de estar ao mesmo tempo dentro e fora leva a protagonista da obra a questionar os conceitos de identidade cultural, casa e pertencimento e a refletir sobre o desafio de viver uma identidade complexa em um processo de contínuas mudanças e construções. Busca-se estabelecer relações com o parangolé, criação artística de Helio Oiticica, em 1964, que só se revela inteiramente na interação com o usuário. O conceito de identidade em caminho expresso por Agualusa, as identidades fragmentárias de Stuart Hall ou a "celebração móvel" da identidade levada a cabo pela protagonista da obra literária, associam-se à dimensão móvel do parangolé, que se transforma continuamente e não demarca um território.

Palavras-chave: migração; identidade; representação artística.

\begin{abstract}
The article analyzes the novel Porto il velo adoro i Queen (2008), by Sumaya Abdel Qader, written by an Italian with Jordanian and Palestinian origins, seeking to deconstruct the stereotypes related to this condition and the double "burdens" of identity imposed to the author. The awareness of being simultaneously inside and outside leads the protagonist to question the concepts of cultural identity, belonging and home, as well to reflect on the challenge of living a complex identity in a process of continuous change and reconstruction. The article seeks to establish relations with the parangolé, Helio Oiticica's artistic creation in 1964, which reveals itself only through the interaction with the user. The concept of identity in the way expressed by Agualusa, the fragmentary identities according to Stuart Hall or the "mobile celebration" of identity undertaken by the protagonist of the literary work, are associated with parangole's mobile dimension, which transforms itself continuously and do not demarcate a territory.
\end{abstract}

Keywords: migration; identity; artistic representation. 